\title{
Comparison of Chemoradiotherapy and Radical Radiotherapy in Patients With Cervical Cancer
}

\author{
Ozlem Yetmen Dogan ${ }^{1, *}$, Ismet Sahinler ${ }^{2}$ \\ ${ }^{1}$ Department of Radiation Oncology, University of Health Sciences, Dr. Lutfi \\ Kirdar Kartal Training and Research Hospital, Istanbul, Turkey \\ ${ }^{2}$ Radiation Oncology Department, Cerrahpasa Faculty of Medicine, Istanbul \\ University- Cerrahpasa, Istanbul Turkey \\ *Corresponding author: Ozlem Yetmen Dogan, Department of Radiation \\ Oncology, University of Health Sciences, Dr. Lutfi Kirdar Kartal Training and \\ Research Hospital, Semsi Denizer Cad. E-5 Karayolu Cevizli Mevkii 34890 \\ Kartal, Istanbul, Turkey. Tel: +9005332262674; Fax: +902163520083; \\ E-mail:dryetmen@gmail.com
}

DOI: $10.30699 /$ mci.4.2.15

Submitted: 8 December 2019

Revised: 29 December 2019

Accepted: 11 February 2020

e-Published: 1 April 2020

\section{Keywords:}

Uterine Cervical

Neoplasms

Radiotherapy

Chemoradiotherapy
Introduction: The current study aimed at comparing the results of radical radiotherapy (RT) or chemoradiotherapy (CRT) in patients with cervical cancer and evaluating the prognostic factors.

Methods: CRT is the standard of care for locally advanced cervical cancer with the five-year survival rate of 30\%-80\%. In 1978-2006, a total of 716 patients with cervical cancer stage IB2-IVB were retrospectively analyzed for RT and CRT. In intracavitary brachytherapy, the median dose was 24 Gy and follow-up was 78 months. CRT was treated with 45 Gy external radiotherapy with cisplatin $40 \mathrm{mg} / \mathrm{m}^{2}$ given once a week. Results: The five-year pelvic control rate was $56.2 \%$ in the radical RT arm and $75.8 \%$ in the combined arm $(\mathrm{P}=0.01)$; disease-free survival and overall survival rates were $47 \%-56.3 \%(\mathrm{P}=0.09)$ and $44.9 \%-52.5 \%(\mathrm{P}=0.03)$, respectively. Treatment failure was detected in $317(50.5 \%)$ of 627 patients in the RT arm and in $30(33.7 \%)$ of 89 patients in the CRT arm (Chi-squared value $=8.86, \mathrm{P}<0.01)$. Treatment failure rate was high in the 1 st two years. Distant metastases were detected in 116 patients in the RT and 17 patients in the CRT arms. Hematological side effect rates in the CRT arm -anemia, thrombopenia, and leukopenia- were $33.7 \%, 13.5 \%$, and $28.1 \%$, respectively. The prevalence of rectitis, cystitis, and skin and subcutaneous fibrosis in the RT arm was $9.4 \%, 4.8 \%$, and $2.2 \%$, and in the CRT arm was $12.4 \%, 11.2 \%$, and $13.5 \%$, respectively.

Conclusions: CRT increased pelvic control and overall survival rate based on the findings; it can be the preferred treatment modality because of its high response rate and acceptable toxicity.

(C) 2020. Multidisciplinary Cancer Investigation

\section{INTRODUCTION}

Cervical cancer is the 2nd most common gynecologic cancer. Approximately $25 \%$ of cervical cancer cases are in advanced stage at diagnosis [1]. In 1999, the National Cancer Institute issued a clinical announcement recommending concurrent cisplatin-based chemoradiotherapy for female patients with cervical cancer due to the results of five randomized phase III trials reporting a $30 \%$ increase in overall survival rate with an acceptable level of toxicity. Concomitant chemoradiotherapy reduces cervical cancer mortality by $30 \%-50 \%$ and is recommended for patients with cervical cancer $[2,3]$. The concurrent use of chemotherapy and radiotherapy creates a 
synergistic effect by increasing the sensitivity of tumor cells to radiation [1, 3-7].

\section{METHODS}

The current retrospective study evaluated patient files from the Department of Radiation Oncology of Cerrahpasa Faculty of Medicine, Istanbul University- Cerrahpasa, Istanbul, Turkey. A total of 716 subjects underwent radical radiotherapy or chemoradiotherapy for cervical cancer from 1978 to 2006. The study was approved by the Institutional Review Board of Istanbul University. The data are summarized in Table 1.

Table 1: Patient Characteristics

\begin{tabular}{|c|c|c|}
\hline & $\begin{array}{c}\text { Radiotherapy, } \\
\text { No.(\%) }\end{array}$ & $\begin{array}{c}\text { Chemoradiotherapy, } \\
\text { No.(\%) }\end{array}$ \\
\hline \multicolumn{3}{|l|}{ Age, yr } \\
\hline$\leq 39$ & $69(11.0)$ & $14(15.7)$ \\
\hline $40-49$ & $121(19.3)$ & $17(19.1)$ \\
\hline $50-59$ & $187(29.8)$ & $25(28.1)$ \\
\hline $60-69$ & $169(27.0)$ & $30(33.7)$ \\
\hline $70-79$ & $69(11.0)$ & $3(3.4)$ \\
\hline 80-89 & $11(1.8)$ & - \\
\hline 90 & $1(0.2)$ & - \\
\hline \multicolumn{3}{|l|}{ Histology } \\
\hline Squamous & $578(92.2)$ & $85(95.5)$ \\
\hline Adeno & $44(7.0)$ & $2(2.0)$ \\
\hline Adenosquamous & $5(0.8)$ & $2(2.0)$ \\
\hline \multicolumn{3}{|l|}{ Grade } \\
\hline I & $115(18.3)$ & $11(12.4)$ \\
\hline II & 198(31.6) & $38(42.7)$ \\
\hline III & $124(19.8)$ & $12(13.5)$ \\
\hline Unknown & $190(30.3)$ & $28(31.4)$ \\
\hline \multicolumn{3}{|l|}{ Stage } \\
\hline IB2 & $40(6.4)$ & $6(6.7)$ \\
\hline IIA & $29(4.6)$ & $1(1.1)$ \\
\hline IIB & $287(45.8)$ & $62(69.7)$ \\
\hline IIIA & $20(3.2)$ & $4(4.5)$ \\
\hline IIIB & $223(35.6)$ & $14(15.7)$ \\
\hline IVA & $14(2.2)$ & - \\
\hline IVB & $14(2.2)$ & $2(2.2)$ \\
\hline \multicolumn{3}{|l|}{ TM size, $\mathrm{cm}$} \\
\hline$<4$ & 101(16.1) & $16(18.0)$ \\
\hline$\geq 4$ & $245(39.1)$ & $73(82.0)$ \\
\hline Unknown & $281(44.8)$ & - \\
\hline \multicolumn{3}{|l|}{$\mathrm{Hb}, \mathrm{g} / \mathrm{dL}$} \\
\hline$<12$ & $276(44.0)$ & $51(57.3)$ \\
\hline$\geq 12$ & $235(37.5)$ & $38(42.7)$ \\
\hline Unknown & $116(18.5)$ & - \\
\hline
\end{tabular}

After the treatment, patients were followed up every three months for the 1st two years, every six months for the following three years, and once a year after the 1st five years. Each follow-up included a gynecological examination and vaginal smear testing. Furthermore, a routine blood test, as well as chest X-ray and radiological examinations were performed every six months, with additional tests in cases of suspected recurrence or metastasis. The current study assessed pelvic control (PC), diseasefree survival (DFS), and overall survival (OS) using Kaplan-Meier estimate and the log rank test [8] in the subjects. The significant factors in univariate analysis were also included in the multivariate analysis. Qualitative data were compared with the Chi-squared test, and Cox regression was used for multivariate analysis [9]. RTOG/EORTC acute and late radiation morbidity scoring schema criteria were used to determine the early side effects and late complications [10].

\section{RESULTS}

For the radiotherapy (RT) group, median pelvic RT dose was $52 \mathrm{~Gy}$, and median course of treatment was 43 days. Median intracavitary brachytherapy dose was $24 \mathrm{~Gy}$, and median follow-up time was 78 months. For the concurrent chemoradiotherapy (CRT) group, $40 \mathrm{mg} / \mathrm{m}^{2}$ cisplatin was concomitantly administered once a week. However, due to simultaneous toxicity, several subjects stopped chemotherapy after a certain number of cycles: four cycles for 24 patients $(26 \%)$, three cycles for 10 patients $(11 \%)$, and two cycles for two patients (2\%). Median pelvic radiotherapy dose was $45 \mathrm{~Gy}$ (45-54), and median treatment time was 38 days. Median intracavitary brachytherapy dose was 27.5 Gy, and median follow-up time was 35 months. For all patients, the two-year PC, DFS, and OS rates were $64.5 \%, 57.9 \%$, and $64.9 \%$ and the five-year rates were $58.3 \%, 47.99 \%$, and $45.9 \%$, respectively. The two- and five-year PC rates were $62 \%$ and $56.2 \%$ for the radical RT group, and $82.8 \%$ and $75.8 \%$ for the CRT group, respectively ( $\mathrm{P}=0.01)$. The two- and five-year DFS rates were $56.5 \%$ and $47 \%$ for the radical RT group, and $67.4 \%$ and $56.3 \%$ for the CRT group, respectively. The DFS rates were higher in the CRT group compared with those of the radial RT group; however the difference was statistically insignificant $(\mathrm{P}=0.09)$. The two- and five-year OS rates were respectively $63 \%$ and $44.9 \%$ for the radical 
RT group, and $78.3 \%$ and $52.5 \%$ for the CRT group $(\mathrm{P}=0.03)$. Treatment failure was noticed in 317 of 627 patients in the radial RT group (50.5\%) as well as 30 of 89 subjects in the CRT group (33.7\%) (Chisquared value $=8.86, \mathrm{P}<0.01)$. Treatment failure was evaluated under three subgroups of local (central, peripheral, central, and peripheral), distant, and combined. Failure rates were high in both treatment groups in the 1st two years. There were 116 and 17 cases of distant metastasis in the radial RT and the CRT groups, respectively. Distant metastases were localized primarily in the para-aortic lymph nodes, the lungs, bones, and liver in the radial RT group, and in the lungs, abdomen, and para-aortic lymph nodes in the CRT group.

\section{Univariate Analysis}

The univariate analysis of the radial RT group indicated that PC and DFS were low for younger patients $(<55$ years). Also, advanced cancers and tumors larger than $4 \mathrm{~cm}$ at diagnosis adversely affected PC, DFS, and OS rates. Hemoglobin levels $<12 \mathrm{~g} / \mathrm{dL}$ and the presence of post-treatment residual tumor were poor prognostic factors for all three parameters. Simultaneous central and peripheral involvement in local recurrence indicated poor outcome for all three parameters (Table 2).

The univariate analysis of the CRT group indicated that PC, DFS, and OS rates were low in advanced cancers. It was observed that $>4$ cycles of chemotherapy improved PC rate. Hemoglobin levels $<12 \mathrm{~g} / \mathrm{dL}$ and the presence of post-treatment residual tumor were poor prognostic factors for PC and DFS. Simultaneous central and peripheral involvement in local recurrence indicated poor outcome for all three parameters (Table 3 ).

\section{Multivariate Analysis}

The multivariate analysis of the radial RT group indicated that PC and DFS rates were affected by the localization of pelvic recurrence and the presence of residual tumors, whereas OS

Table 2: Univariate Analysis Results in the RT Arm ${ }^{\mathrm{a}}$

\begin{tabular}{|c|c|c|c|c|c|c|}
\hline & \multicolumn{6}{|c|}{ Radiotherapy Treatment } \\
\hline & \multicolumn{2}{|c|}{ Pelvic Control } & \multicolumn{2}{|c|}{ Disease-Free Survival } & \multicolumn{2}{|c|}{ Overall Survival } \\
\hline & 3 years, $\%$ & P Value & 3 years, $\%$ & P Value & 3 years, $\%$ & P Value \\
\hline Age, yr & & $<0.001$ & & 0.01 & & 0.32 \\
\hline$<55$ & 50.3 & & 46.1 & & 49.90 & \\
\hline$\geq 55$ & 66.2 & & 55.7 & & 65.10 & \\
\hline Stage & $<0.001$ & & $<0.001$ & & $<0.001$ & \\
\hline IB2 & 96.7 & & 92.8 & & 83.70 & \\
\hline IIA & 79.4 & & 76.8 & & 81.30 & \\
\hline IIB & 67.1 & & 58.8 & & 62.70 & \\
\hline IIIA & 55.0 & & 50.0 & & 47.60 & \\
\hline IIIB & 44.7 & & 38.9 & & 41.60 & \\
\hline IV & 19.8 & & 08.6 & & 11.60 & \\
\hline TM size, $\mathrm{cm}$ & & 0.029 & & $<0.001$ & & $<0.001$ \\
\hline$<4$ & 62.4 & & 48.2 & & 56.6 & \\
\hline$\geq 4$ & 47.6 & & 38.5 & & 44 & \\
\hline Residual Tm & & $<0.001$ & & $<0.001$ & & $<0.001$ \\
\hline Yes & 4.70 & & 3 & & 5 & \\
\hline No & 75.3 & & 66 & & 70 & \\
\hline Local Relapse & & $<0.001$ & & $<0.001$ & & $<0.001$ \\
\hline Central & 4 & & 4 & & 20 & \\
\hline Peripheral & 10 & & 10 & & 22 & \\
\hline Central+Peripheral & 5 & & 04.5 & & 12 & \\
\hline $\mathrm{Hb}, \mathrm{g} / \mathrm{dL}$ & & $<0.001$ & & $<0.001$ & & $<0.001$ \\
\hline$<12$ & 47 & & 40 & & 43 & \\
\hline$\geq 12$ & 66 & & 59 & & 66.30 & \\
\hline
\end{tabular}


Table 3: Univariate Analysis Results in the CRT Arm ${ }^{\mathrm{a}}$

\begin{tabular}{|c|c|c|c|c|c|c|}
\hline & \multicolumn{6}{|c|}{ Chemoradiotherapy Treatment } \\
\hline & \multicolumn{2}{|c|}{ Pelvic Control } & \multicolumn{2}{|c|}{ Disease-Free Survival } & \multicolumn{2}{|c|}{ Overall Survival } \\
\hline & 3 years, $\%$ & P Value & 3 years, $\%$ & P Value & 3 years, $\%$ & P Value \\
\hline Age, yr & & 0.1 & & 0.17 & & 0.18 \\
\hline$<55$ & 68.1 & & 53.6 & & 56 & \\
\hline$\geq 55$ & 83.4 & & 65.5 & & 69.3 & \\
\hline Stage & & 0.01 & & $<0.001$ & & 0.009 \\
\hline IB2 & 100 & & 100 & & 100 & \\
\hline IIA & 100 & & 83.3 & & 80.0 & \\
\hline IIB & 80.5 & & 75.0 & & 69.6 & \\
\hline IIIA & 75.1 & & 64.4 & & 50.0 & \\
\hline IIIB & 51.0 & & 42.9 & & 27.3 & \\
\hline IV & 0 & & 0 & & 0 & \\
\hline Tumor Size, cm & & 0.14 & & 0.19 & & 0.28 \\
\hline$<4$ & 81.9 & & 64.5 & & 68.2 & \\
\hline$\geq 4$ & 68.5 & & 53.7 & & 57.1 & \\
\hline Chemotherapy Treatment, cycle & & 0.05 & & 0.8 & & 0.53 \\
\hline$<4$ & 57.1 & & 59.9 & & 67.5 & \\
\hline$\geq 4$ & 78.8 & & 58.3 & & 62 & \\
\hline Residual Tm & & $<0.001$ & & 0.03 & & 0.21 \\
\hline Yes & 84.4 & & 45.6 & & 5 & \\
\hline No & 54.3 & & 65.4 & & 70 & \\
\hline Local Relapse & & $<0.001$ & & $<0.001$ & & $<0.001$ \\
\hline Central & 10.5 & & 9 & & 35 & \\
\hline Peripheral & 66 & & 33 & & 66 & \\
\hline Central+Peripheral & 0 & & 0 & & 0 & \\
\hline $\mathrm{Hb}, \mathrm{g} / \mathrm{dL}$ & & 0.02 & & 0.016 & & 0.12 \\
\hline$<12$ & 67 & & 48.1 & & 55.3 & \\
\hline$\geq 12$ & 87.2 & & 73.2 & & 57.1 & \\
\hline
\end{tabular}

rate was affected by the localization of pelvic recurrence and the stage of the disease (Table 4). Multivariate analysis of the CRT group indicated that PC, DFS, and OS rates were lower in advanced cancers, and the presence of residual tumors negatively affected PC. Localization of pelvic recurrence significantly affected $\mathrm{PC}, \mathrm{DFS}$, and OS; hemoglobin levels $<12 \mathrm{~g} / \mathrm{dL}$ adversely affected DFS rate (Table 4).

\section{Side Effects}

In the radial RT group, the prevalence of grade II skin side effects was $9.9 \%$ and grade I diarrhea was $12.1 \%$. In the CRT group, the prevalence of grade I radiation dermatitis was $25.8 \%$ and grade I diarrhea was $32.6 \%$. Hematologic side effects were more common in the CRT group than the radial RT group. The prevalence of grade I anemia, thrombocytopenia, and grade II leukopenia was

Table 4: Multivariate Analysis Results of the CRT and the RT Arm ${ }^{\mathrm{a}}$

\begin{tabular}{lcccccc}
\hline & \multicolumn{2}{c}{ Pelvic Control, P Value } & \multicolumn{2}{c}{ Disease-Free Survival, P Value } & \multicolumn{3}{c}{ Overall Survival, P Value } \\
\cline { 2 - 8 } & CRT & RT & CRT & RT & \multicolumn{1}{c}{ CRT } & RT \\
\hline Stage & 0.03 & 0.6 & 0.02 & 0.06 & 0.04 & 0.005 \\
Residual Tm & 0.01 & $<0.001$ & 0.50 & 0.06 & 0.60 & 0.400 \\
Local relapse & $<0.001$ & $<0.001$ & $<0.001$ & $<0.001$ & 0.04 & $<0.001$ \\
Hb & 0.10 & 0.7 & 0.03 & $<0.001$ & 0.80 & 0.700 \\
\hline
\end{tabular}

a $\mathrm{P}<0.05$ was considered as the level of significance 
$33.7 \%, 13.5 \%$, and $28.1 \%$, respectively. The rectal, bladder, and skin side effects and subcutaneous radiation fibrosis were more common in the CRT group. The prevalence of grade II rectitis, cystitis, and radiation dermatitis and subcutaneous fibrosis was $9.4 \%, 4.8 \%$, and $2.2 \%$ in the radial RT group, and $12.4 \%, 11.2 \%$, and $13.5 \%$ in the CRT group, respectively. There were no grade IV side effects in either group. There were no cases of nephrotoxicity or ototoxicity in the CRT group.

\section{DISCUSSION}

Until the 2000s, cervical cancers were treated with radiotherapy; local control rates ranged $35 \%$ to $90 \%$, and two-thirds of all recurrences were local $[1,4,5]$. Researchers worked on many agents to improve the effectiveness of radiotherapy, including cisplatin, 5- fluorouracil (FU), mitomycin-C, and hydroxyurea. Radiotherapy was used alone to treat cervical cancers, until a clinical announcement was issued by the National Cancer Institute (NCI) in 1999. Concomitant chemoradiotherapy aims to increase radio-sensitivity and decrease tumor cell repopulation through several different mechanisms: it prevents the repair of radiationinduced DNA damage, reassorts tumor cells into radiation-sensitive phases, and reoxygenates radiation-resistant hypoxic tumor cells $[1,3,11$, 12]. Gynecologic Oncology Group conducted a trial (GOG \#85) on 368 patients with cervical cancer (stages IIB, III, or IVA). The five-year survival rate was $62 \%$ for patients treated with cisplatin and 5-FU, and $50 \%$ for patients treated with hydroxyureabased concomitant chemoradiotherapy. However, acute gastrointestinal toxicity was higher in the cisplatin/5-FU group [13]. In another study by the Gynecologic Oncology Group (GOG \#120), 526 cases (stages IIB-IVA) were reviewed. The DFS and OS rates of the patients treated with cisplatin (single-agent or combination) were higher than those of the ones treated with hydroxyurea $(\mathrm{P}<0.01)$ [12]. Radiotherapy Oncology Group (RTOG \#9001) conducted a phase III trial on patients with cervical cancer (stages IB-IVA), and found that DFS and OS rates were higher among patients receiving concurrent chemoradiotherapy [7].

To compare concurrent therapy with radiotherapy alone, Wong et al., used $25 \mathrm{mg} / \mathrm{m}^{2}$ of cisplatin to treat patients with cervical cancer (stages IIB-III). They found that the treatment response rates were higher in the cisplatin-based chemoradiotherapy group; however, local control and survival rates were not significantly different between the groups [14]. In the phase III randomized study of the Gynecologic Oncology Group (GOG \#123), it was observed that at the end of 36 months follow-up, the PC, DFS, and OS rates increased in patients receiving weekly concomitant cisplatin treatments. The three-year survival rates were $83 \%$ for the chemoradiotherapy group, and $74 \%$ for the radiotherapy group [12]. In contrast to these five studies, the study of the National Cancer Institute of Canada (NCIC) did not find a significant difference in terms of survival rate after 82 months follow-up [13]. Finally, a metaanalysis (2008) on 18 randomized trials showed that chemoradiotherapy improved OS rates in cervical cancer. Cisplatin-based chemoradiotherapy also increased DFS and OS rates [13].

The main treatment modality in cervical cancer is radical radiotherapy with concomitant cisplatinbased chemotherapy. The current study found that concurrent chemoradiotherapy increased the fiveyear PC and OS rates from $56.2 \%$ and $45 \%$ to $75.8 \%$ and $53 \%$, respectively $(\mathrm{P}=0.01, \mathrm{P}=0.03)$. The current study also found that the five-year DFS rate was higher in the CRT group than the radial RT group (56.3\% vs. $45 \%$ ); however, the difference was not statistically significant $(\mathrm{P}=0.09)$. The current study results were consistent with those of the reviewed literature. Cisplatin is an antineoplastic agent preferred for concomitant chemotherapy due to its low bone marrow toxicity. One of the major side effects of concurrent chemotherapy is hematological toxicity. In their study on stage IB2 cervical cancer, Keys et al., found that chemoradiotherapy was associated with higher hematological toxicity, and higher grade I and II genitourinary side effects; however, late side effects were not significantly different from those of the patients receiving radical radiotherapy [5]. The current study also found that hematological toxicity was more common in the CRT group (52.8\%). Also, $28.1 \%$ of patients had grade II leukopenia and $27 \%$ had grade II gastrointestinal side effects; thus, the current study toxicity results were comparable to those of Keys et al.; however, the current study late side effects findings were somewhat different, where in the CRT group, the rates of rectitis and cystitis were $12.4 \%$ and $11.2 \%$, respectively, and late gastrointestinal side effects were slightly higher in the CRT group. 
Studies show that chemoradiotherapy, especially with cisplatin, improves survival rate of cervical cancer. In the current study, five-year survival rates were $44.9 \%$ and $52.5 \%$ in the radial RT and CRT groups, respectively. The higher survival rates of the CRT group indicated that concurrent chemoradiotherapy can decrease treatment failure rates. Treatmentrelated side effects, most particularly hematological toxicity, were more common in the CRT group. However, these side effects were evaluated as tolerable.

\section{ACKNOWLEDGMENTS}

None declared.

\section{CONFLICT OF INTEREST}

The authors declared no conflict of interest.

\section{ETHICS APPROVAL}

The study was approved by the Institutional Review Board of Istanbul University.

\section{REFERENCES}

1. Lehman M, Thomas G. Is concurrent chemotherapy and radiotherapy the new standard of care for locally advanced cervical cancer? Int J Gynecol Cancer. 2001;11(2):8799. DOI: 10.1046/j.1525-1438.2001.01008.x PMID: 11328406.

2. Roberts KB, Urdaneta N, Vera R, Vera A, Gutierrez $\mathrm{E}$, Aguilar $\mathrm{Y}$, et al. Interim results of a randomized trial of mitomycin $\mathrm{C}$ as an adjunct to radical radiotherapy in the treatment of locally advanced squamous-cell carcinoma of the cervix. Int J Cancer. 2000;90(4):206-23. DOI: $\quad 10.1002 / 1097-0215(20000820) 90: 4<206::$ Aidijc4>3.0.Co;2-o.

3. Spensley S, Hunter RD, Livsey JE, Swindell R, Davidson SE. Clinical outcome for chemoradiotherapy in carcinoma of the cervix. Clin Oncol. 2009;21(1):49-55. DOI: 10.1016/j.clon.2008.10.014 PMID: 19081712.

4. Rose PG. Locally advanced cervical carcinoma: the role of chemoradiation. Semin Oncol. 1994;21(1):47-53.

5. Rose PG, Bundy BN, Watkins EB, Thigpen JT, Deppe G, Maiman MA, et al. Concurrent Cisplatin-Based Radio- therapy and Chemotherapy for Locally Advanced Cervical Cancer. New Engl Med. 1999;340(15):1144-53. DOI: 10.1056/nejm199904153401502 PMID: 10202165.

6. Keys HM, Bundy BN, Stehman FB, Muderspach LI, Chafe WE, Suggs CL, et al. Cisplatin, Radiation, and Adjuvant Hysterectomy Compared with Radiation and Adjuvant Hysterectomy for Bulky Stage IB Cervical Carcinoma. New Engl J Med. 1999;340(15):1154-61. DOI: 10.1056/ nejm199904153401503 PMID: 10202166.

7. Pignon JP, Bourhis J, Domenge C, Designé L. Chemotherapy added to locoregional treatment for head and neck squamous-cell carcinoma: three meta-analyses of updated individual data. Lancet. 2000;355(9208):949-55. DOI: 10.1016/S0140-6736(00)90011-4.

8. Kaplan EL, Meier P. Nonparametric Estimation from Incomplete Observations. J Am Stat Assosc. 1958;53(282):45781. DOI: $10.1080 / 01621459.1958 .10501452$.

9. Cox DR. Regression Models and Life-Tables. J Roy Stat Soc. 1972;34(2):187-202. DOI: 10.1111/j.2517-6161.1972. tb00899.x.

10. Cox JD, Stetz J, Pajak TF. Toxicity criteria of the Radiation Therapy Oncology Group (RTOG) and the European organization for research and treatment of cancer (EORTC). Int J Radiat Oncol Biol Phys. 1995;31(5):1341-6. DOI: 10.1016/0360-3016(95)00060-C.

11. Thomas G, Dembo A, Fyles A, Gadalla T, Beale F, Bean $\mathrm{H}$, et al. Concurrent chemoradiation in advanced cervical cancer. Gynecol Oncol. 1990;38(3):446-51. DOI: 10.1016/0090-8258(90)90089-4.

12. Whitney CW, Sause W, Bundy BN, Malfetano JH, Hannigan EV, Fowler J, Wesley C, et al. Randomized comparison of fluorouracil plus cisplatin versus hydroxyurea as an adjunct to radiation therapy in stage IIB-IVA carcinoma of the cervix with negative para-aortic lymph nodes: a Gynecologic Oncology Group and Southwest Oncology Group study. J Clin Oncol. 1999;17(5):1339-. DOI: 10.1200/ JCO.1999.17.7.2055 PMID: 10334517.

13. Wong L, Ngan H, Cheung A, Cheng D, Ng T, Choy D. Chemoradiation and adjuvant chemotherapy in cervical cancer. J Clin Oncol. 1999;17(7):2055-. DOI: 10.1200/ JCO.1999.17.5.1339 PMID: 10561258.

14. Pearcey R, Brundage M, Drouin P, Jeffrey J, Johnston D, Lukka $\mathrm{H}$, et al. Phase III trial comparing radical radiotherapy with and without cisplatin chemotherapy in patients with advanced squamous cell cancer of the cervix. J Clin Oncol. 2002;20(4):966-72. DOI: 10.1200/JCO.1999.17.7.2055. 